\title{
Genotypes of hepatitis B virus identified in patients tested prior to endoscopy from a Teaching Hospital in the Central Province of Sri Lanka
}

\author{
D G D Jayasuriya, F Noordeen, F N N Pitchai
}

(Index words: Hepatitis B virus, genotyping, S gene, polymerase chain reaction, DNA sequencing)

\begin{abstract}
The present study was carried out to identify the hepatitis $B$ virus (HBV) genotypes in six patients attending the surgical clinic who were positive for hepatitis $B$ surface antigen. DNA was extracted from the serum of patients and subjected to a modified nested PCR to detect a 585 bp region within the $\mathrm{S}$ gene of the HBV genome. Positive PCR products were purified and sequenced via a cycle sequencing method. The sequence data were analyzed with reference sequences in the HepSEQ database to identify the particular HBV genotype of the samples. Nested PCR for the $S$ gene of the HBV genome was positive in 2 out of 6 samples. The genotyping and sequence analysis of the PCR products showed HBV genotype A with a homology of $98 \%$ to the reference sequences in the HepSeq database.
\end{abstract}

Ceylon Medical Journal 2015; 60: 62-4

\section{Introduction}

Hepatitis B virus (HBV) is an enveloped DNA virus that infects the hepatocytes of humans. HBV is transmitted from person to person by sexual contact or mother to baby during delivery or afterwards or from blood products during transfusion or accidental inoculation in a healthcare setting [1]. HBV infection can give rise to either acute infection or chronic disease which can lead to cirrhosis and hepatocellular carcinoma in the long term [1]. The HBV genome is a partially double stranded circular DNA molecule, 3200 base pairs long [2]. Sequencing and phylogenetic studies of the genome indicate the existence of eight distinct genotypes (A$\mathrm{H})$ and numerous sub types of HBV. These genotypes and sub types have risen from nucleotide substitution mutations occurring at an estimated rate of 1.4-3.2 $\times 10^{-} 5$ per year due to the low proof reading capability of the viral polymerase during replication. Replication of the HBV genome unlike other DNA viruses occurs via an intermediate RNA synthesis process involving the action of an error prone viral reverse transcriptase giving rise to mutations at a higher rate compared to that of other DNA viruses. The genotypes of the virus are known to differ from each other by more than $8 \%$ of their genome while differences of at least $4 \%$ account for their varied subtypes [3]. Identifying the HBV genotypes of chronically infected individuals in a population is useful in determining the available treat-ment options and predicting the treatment outcomes especially when the chronic HBV infection has evolved to cause the initial fibrotic changes in the liver. DNA sequencing is the gold standard for HBV genotyping [3]. Whole genome sequencing followed by phylogenetic analysis show promising results but these are neither time efficient nor cost effective. A more efficient and accurate method involving the amplification of a target region encompassing genotypic variability, followed by sequence analysis for genotype identification would be a more appropriate method. This study has used such a method by targeting the HBV S gene for genotypic variability.

\section{Methods}

A total of six HBsAg positive serum samples collected between $2007-2011$ and stored at $-20^{\circ} \mathrm{C}$ from were analyzed. All samples were from individuals from the Central Province referred from the Surgical Clinic of the Teaching Hospital, Peradeniya prior to endoscopy. Sera of healthy adults that were negative for HBsAg were used as negative controls. Two hundred $\mu \mathrm{l}$ of serum was used for DNA extraction. Manufacturer's instructions (Nucleo Spin ${ }^{\circledR}$ Tissue Kit, Germany) were followed. Sixty $\mu l$ of DNA was extracted from each sample.

The extracted DNA was then subjected to a nested PCR protocol [4] that was later modified to suit the local laboratory conditions. The first round of PCR was carried out using the forward and reverse outer primers PreS2 (5'-GGGACACCATATTCTTGG-3') and SIR ( 5 ' -TTAGGGTTTAAATGTATACCCA-3') to amplify a region between the PreS1 and $\mathrm{S}$ genes which would result in a $1025 \mathrm{bp}$ amplicon. A total volume of $20 \mu \mathrm{l}$ of the

Department of Microbiology, Faculty of Medicine, University of Peradeniya, Sri Lanka.

Correspondence: FN, e-mail: <faseeha.noordeen12@gmail.com>. Received 5 December 2014 and revised version accepted 13 February 2015. 
master mix was used as follows; $5 \mu$ l of $5 \times$ buffer, $1.25 \mu \mathrm{l}$ of $2 \mathrm{mM}$ dNTPs, $1.25 \mu \mathrm{l}$ of $5 \mathrm{U}$ Taq polymerase, $6.3 \mu 1$ of nuclease free water along with $5 \mu$ l of the extracted DNA template to make up to a total volume of $25 \mu$ l. The thermal profile used in amplification was as follows; an initial denaturation of $3 \mathrm{~min}$ at $94^{\circ} \mathrm{C}$ followed by 40 cycles of denaturation, annealing and polymerization at $94^{\circ} \mathrm{C}$ for $45 \mathrm{~s}, 58^{\circ} \mathrm{C}$ for $1 \mathrm{~min}$ and $72^{\circ} \mathrm{C}$ for $1 \mathrm{~min}$, respectively. This was followed by a final extension of $72^{\circ} \mathrm{C}$ for $10 \mathrm{~min}$.

The $2^{\text {nd }}$ round of PCR was carried out using the same master mix composition as for the first PCR, but using different primers YS1 (GCGGGGTTTTTCTTGTTGA) and YS2 (GGGACTCAAAGATGTTGTACAG) that amplify a $585 \mathrm{bp}$ region within the first amplicon (1025 bp). Five $\mu \mathrm{l}$ of the first PCR product was used as the template making a final volume of $25 \mu$ l. The thermal profile used was identical to that of the first PCR. The final PCR products were resolved on a $2 \%$ agarose gel and visualised.

The purified PCR product was subjected to sequencing using the Genetic Analyzer 3130 (Applied Biosystems; Sequencing Analysing software V5.2). The sequence was compared with reference sequences in the HepSEQ database to identify the HBV genotype of the sample.

\section{Results}

Nested PCR gave bands of 585 bp in conjunction with the positive control (Figure 1) for only two of the 6 HBsAg positive patients' samples. Genotyping and sequence analysis carried out on one positive sample revealed a sequence of 517 bps with a $97.49 \%$ homology to reference sequences of HBV genotype A. The other positive sample revealed a sequence of $235 \mathrm{bps}$ with a $97.86 \%$ homology to reference sequences of HBV genotype A (Figure 2).

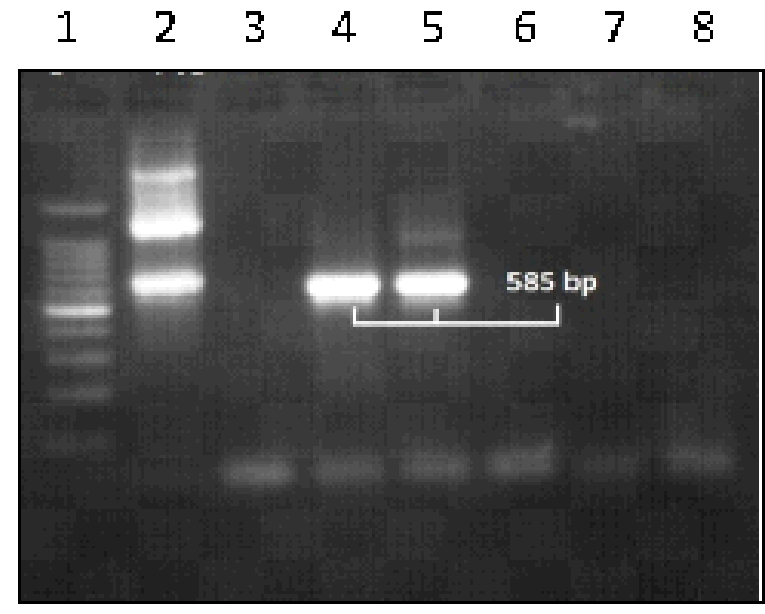

Figure 1. Agarsoe gel profile of PCR products from $5 \mathrm{HBsAg}$ positive serum samples. Lane 1 is a $100 \mathrm{bp}$ marker and lane 2 is the $\mathrm{HBV}$ positive control. Lane 3 (negative control, lanes 4 and 5 are samples that were positive by PCR showing a band size of $585 \mathrm{bp}$ ). Lanes 6,7 and 8 are samples negative for PCR.

\section{Discussion}

Nested PCR was positive for 2 of the 6 samples with the expected band size of $585 \mathrm{bps}$ and the other samples did not give a positive PCR result suggesting that though these samples were positive for $\mathrm{HBs} \mathrm{Ag}$ they were negative for HBV DNA. This might be due to the high number of HBsAg particles but lack of HBV in the sera [5]. Another reason for this finding would be that the blood samples from the corresponding patients would have been obtained in the latter rather than early phases of chronic HBV carriage where the levels of HBV DNA are likely to be

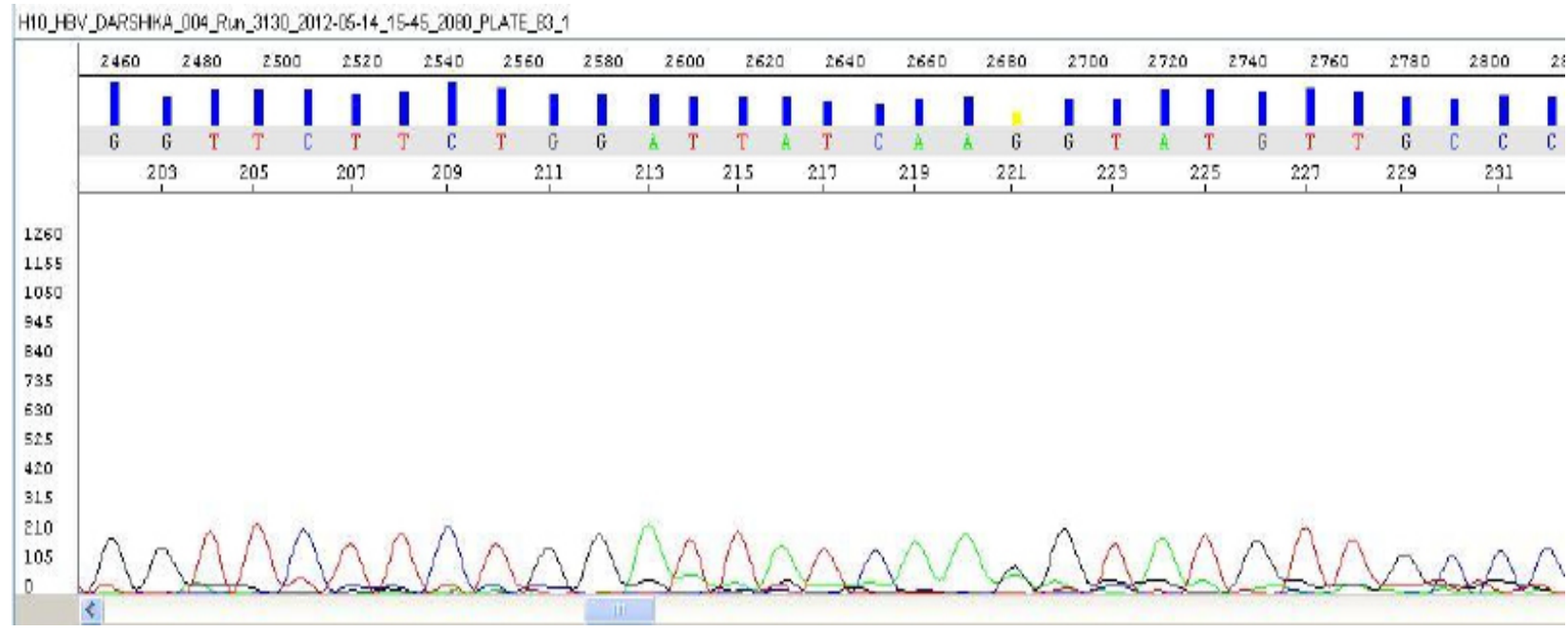

Figure 2. Electrophorogram of HBV DNA of positive sample 5. 
low in the serum due to clearance by the immune system resulting in negative PCR [6].

Genotyping and sequence analysis results carried out on the PCR positive samples 4 and 5 revealed sequences of 517 and $235 \mathrm{bps}$ which were smaller than the expected target sequence size of $585 \mathrm{bp}$ and this might be due to the physical stress exerted on the PCR products during purification prior to sequencing that may have resulted in degradation of the PCR products. Sequence analysis of both PCR products gave a homology of almost $98 \%$ to HBV genotype A instead of the expected $100 \%$, this 2 to $4 \%$ heterogeneity may be attributed to different recombinants, quasi-sub-genotypes or differences in the A1 and A2 sub-genotypes. It is also worthy to note that the HepSEQ tool used here utilizes only the polymerase or surface genes for genotype identification that allows the identification of any escape mutants, but is less accurate for detecting any recombinants if they are present in the sample sequences [7].

According to previous studies genotype A of HBV is pandemic and is predominantly found in the USA, Northwest Europe, Africa and Asia and this remains consistent with results of the current study [3]. However, a study done in Colombo, Sri Lanka on prevailing HBV genotypes in a small cohort of patients with chronic hepatitis $\mathrm{B}$ indicates that HBV genotype $\mathrm{A}(8 \%)$ occurrs at a lower rate than HBV genotype B (36\%), C (16\%) and D $(12 \%)$ [8]. Findings from this study are different to results of our study. Both studies did not include representative samples and these findings may indicate a possible difference in HBV genotypes in different areas in the country. This point emphasises the need for identification of prevalent genotypes in different localities of the country which would lead to better understanding of the spread and distribution of HBV genotypes in Sri Lanka.

The study shows HBV genotype A in the small sample tested, the findings are similar to that of many other studies that claim HBV A to be the predominant circulating genotype in South Asia. Furthermore, the study can be used as a basis for future HBV characterisation, genoty-ping and epidemiological studies in Sri Lanka.

\section{Acknowledgements}

We thank Mr. AMSB Abeykoon, Staff Technical Officer in the Virology Laboratory of the Department of Microbiology, Faculty of Medicine, University of Peradeniya, who provided technical assistance.

\section{Conflicts of interest}

We declare that there are no conflicts of interest.

\section{References}

(1) Hepatitis B general fact sheet. Centre for Disease Control and Prevention. June 2010; Publication no. 21-1073.

(2) Guettouche T, Hnatyszyn HJ. Chronic hepatitis B and viral genotype: the clinical significance of determining HBV genotypes Antivir Ther 2005; 10: 593-604.

(3) Guirgis BSS, Abbas RO, Azzazy HME. Hepatitis B virus genotyping: current methods and clinical implications. Int J Infect Dis 2010; 14: 941-53.

(4) Zeng GB, Wen SJ, Wang ZH, Yan L, Sun J, Hou JL. A novel hepatitis $\mathrm{B}$ virus genotyping system by using restriction fragment length polymorphism patterns of $\mathrm{S}$ gene amplicons. World J Gastroenterol 2004; 10: 3132-6.

(5) Kaneko S, Miller RH, Feinestone SM, et al. Detection of serum hepatitis B virus DNA in patients with chronic hepatitis using the polymerase chain reaction assay. Proc Natl Acad Sci USA 1989; 86: 312- 6.

(6) Lavanchy D. Hepatitis B virus epidemiology, disease burden, treatment, and current and emerging prevention and control measures. $J$ Viral Hepat 2004; 11: 97-107.

(7) Pourkarim MR, Olyaee SAB, Kurbanov F, Ranst MV, Tacke F. Molecular identification of hepatitis B virus genotypes/ subgenotypes: Revised classification hurdles and updated resolutions. World J Gastroentorol 2014; 20: 7152-68.

(8) Manamperi A, Gunawardene N.S, Wellawatta C, et al. Hepatitis B virus (HBV) genotypes in a group of Sri Lankan patients with chronic infection. Trop Biomed 2011; 28: 320-4. 